\title{
Identification of Novel Genes Involved in the Development of the Sword and Gonopodium in Swordtail Fish
}

\author{
Nils Offen, Axel Meyer, and Gerrit Begemann*
}

\begin{abstract}
Male swordtail fish of the genus Xiphophorus develop a sword, a colourful extension of the caudal fin, that evolved by sexual selection through female choice. Swords and gonopodia, an intromittent organ developing from the male anal fin, can be prematurely induced by exogenous testosterone, offering the opportunity to examine the identity and expression profiles of genes required during various stages of fin metamorphosis. Here, we employed suppression subtractive hybridisation to identify genes specifically up-regulated during two early stages of sword and gonopodium development. We identified 128 different sequences with significant similarity to known genes and characterized the rack $1, d u s p 1, k l f 2$, and $t m s \beta$-like genes as specifically up-regulated in developing as well as regenerating fin rays of the sword and gonopodium. We show that some of these genes follow distinct expression profiles in swords and gonopodia, suggesting differences in the genetic networks underlying the development of anal and caudal fin modifications.
\end{abstract}

Key words: sword development; sword; gonopodium; SSH; rack1; dusp1; klf2; tms $\beta$; Xiphophorus; swordtail; fin metamorphosis

\section{INTRODUCTION}

Swordtail fish are a suitable and popular model for the study of sexual selection in a vertebrate organism (reviewed in Rosenthal and Garcià de Leon, 2006). Male fish of the Green Swordtail, $X i$ phophorus helleri, possess a sword, a prominent extension of the caudal fin with contrasting pigmentation, that was first introduced by Charles Darwin as an example of a sexually selected trait in fishes (Darwin, 1871). The sword is composed of approximately four elongated ventral fin rays covered by pigment cells that form a distinctive pattern of a yellowish stripe flanked by black borders (Fig. 1A,B) (Basolo and Trainor, 2002). Both traits, sword length and coloration, have been shown to be important for mating success (Rosenthal and Evans, 1998; Basolo and Trainor, 2002). In contrast to swordtails, male platyfish, a monophyletic clade within the genus Xiphophorus, lack a sword, even though females of some platy species show a bias for sworded males (Basolo, 1990, 1995). For this reason, the evolutionary history of the sword has been stud- ied intensively to discover the origin of sword gains and losses. Molecular data support the hypothesis that all extant Xiphophorus species descend from a sworded ancestor. In this scenario, the sword was secondarily lost in the lineage leading to the platyfish (Meyer et al., 1994, 2006; Meyer, 1997). Even though the sword is an important trait that is evaluated by females during courtship, its evolutionary loss in platyfish might have been caused by high predation pressure associated with its maintenance. It has been shown that

Additional Supporting Information may be found in the online version of this article.

Department of Biology, Lehrstuhl für Zoologie und Evolutionsbiologie, University of Konstanz, Konstanz, Germany

Grant Sponsor: Deutsche Forschungsgemeinschaft (DFG); Grant number: BE 1902/4-1; Grant sponsor: Landesgraduiertenförderung (LGF)

Konstanz, 78457 Konstanz, Germany. E-mail: gerrit.begemann@uni-konstanz.de 

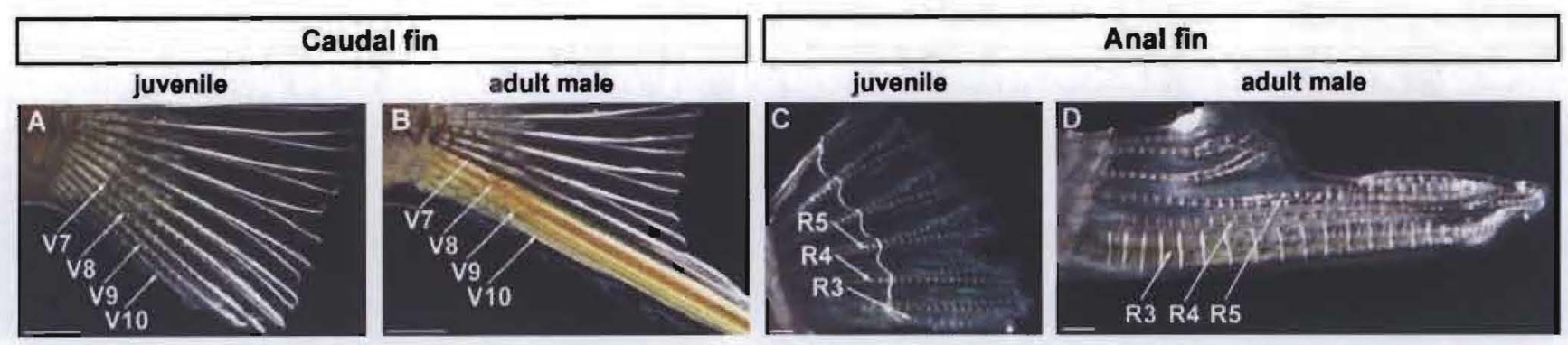

E
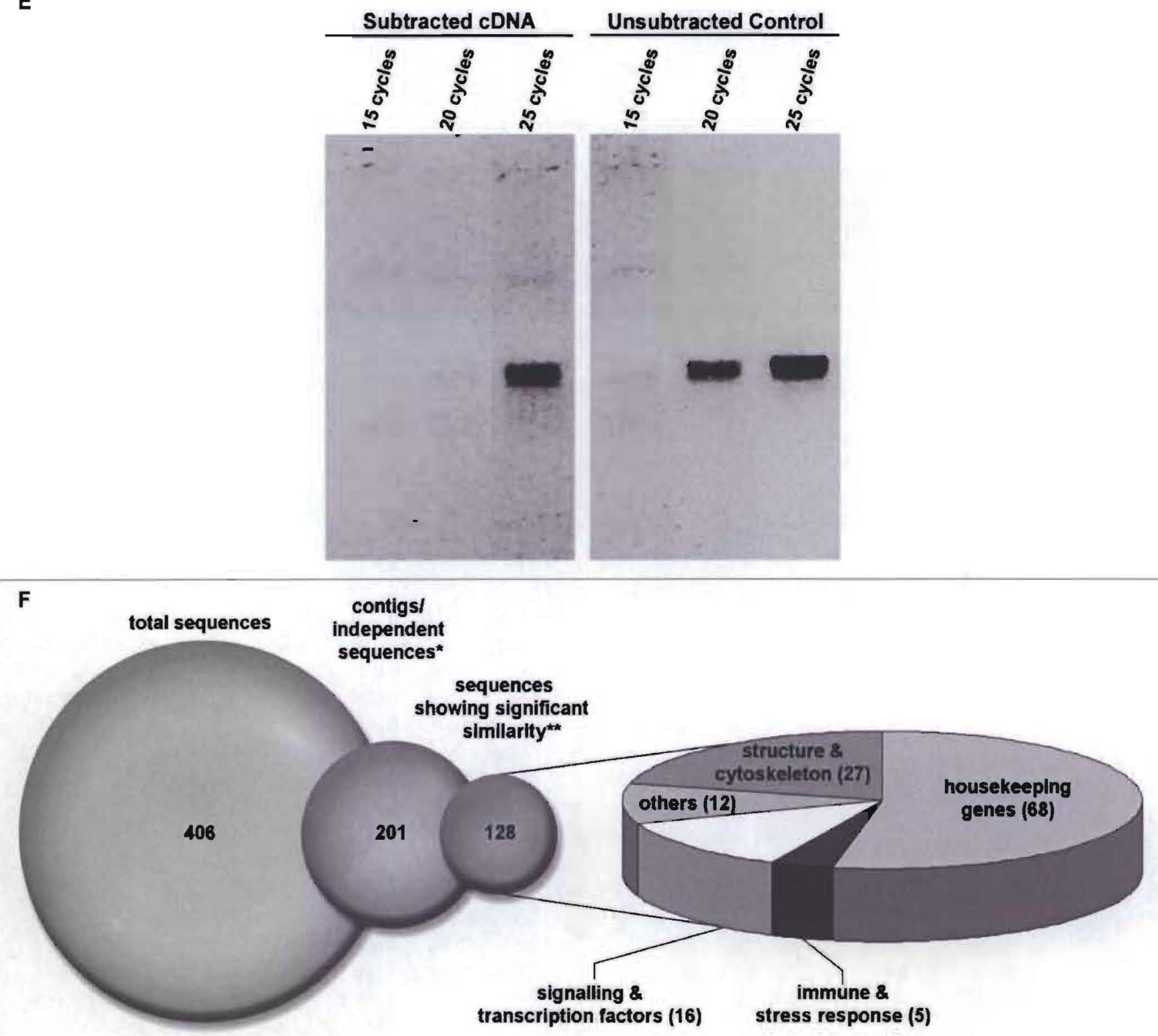

Fig. 1. Efficiency of subtractive hybridisation and overview of obtained genes. A, B: Caudal fins of Xiphophorus helleri males before (A) and after (B) sexual maturation; four ventral caudal fin rays, V7-10, contribute to the sword. C, D: Anal fins of juvenile (C) and adult (D) male $X$. helleri; three fin rays, R3-5, form the gonopodium, an intromittent organ for internal fertilisation. E: A fragment of the gapdh transcript was amplified from subtracted and unsubtracted cDNA, derived from testosterone-treated fins. PCR was performed for 15,20 , and 25 cycles using species-specific oligoncleotide primers. Amplification of the gapdh fragment is detected five cycles later in the subtracted rather than in the unsubtracted cDNA, suggesting successful reduction of common transcripts in the subtracted pool. F: A total of 406 size-selected clones from the SSH-library were sequenced and analysed Sequences fell into 201 independent contigs and singletons, of which 128 showed similarity to known genes from other species. These 128 positive hits were grouped into five categories according to their predicted functions. "A contig/sequence was scored as independent, when no significant overlap with other contigs/sequences was found; "*a sequence was considered to be similar to a sequence in the database if the e-value (obtained by Blast) was $e^{-15}$ or smaller. Scale bars $=1 \mathrm{~mm}(A, B), 500 \mu \mathrm{m}(C, D)$. 
males with longer swords experience higher metabolic costs during swimming, that predators are attracted by the conspicuous ornamentation of the sword, and that exposure to predators can reverse the female bias for swords (Rosenthal et al., 2001; Basolo and Alcaraz, 2003; Johnson and Basolo, 2003). Therefore, the opposing effects of sexual and natural selection could almost certainly also lead to sword loss.

On the molecular level, however, the evolutionary changes that caused the gain or loss of the sword have not yet been revealed. To dissect the molecular pathways involved in these processes, it will be important to identify the genes that regulate caudal fin metamorphosis into the sword and to resolve the evolutionary modifications that led to the loss or gain of the sword. This can be achieved within a phylogenetic framework of the entire genus that includes swordtails and platyfish. Hybridisation experiments between $X$. helleri and $X$, cortezi suggested that multiple genes, collectively termed "sword genes" ("Schwertgene"), contribute to sword formation (Zander and Drwillo, 1969). In male fish, the endogenous synthesis of androgens during sexual maturation, or the artificial exposure to testosterone, trigger the signalling events that induce the activation of sword genes (Dzwillo, 1962, 1964). Moreover, testosterone also controls the metamorphosis of the male anal fin into an intromittent organ, the gonopodium (Fig. 1C,D) (Gordon et al., 1942; Grobstein, 1942). More recently, it has been shown that the two longest rays, which form the core of the sword, act as signalling centers that promote growth in the neighbouring fin rays (Eibner et al., 2008). Even though the molecular identity of the organizing activity remains to be determined, a number of candidate genes have been shown to be activated during both sword and gonopodium development. Zauner et al. (2003) hypothesised that the genetic network controlling gonopodium development was evolutionarily co-opted to form the sword. This idea is supported by the observation that a gene network, in which signalling through Fibroblast growth factor receptor 1 (Fgfr1) positively controls the expression of $m s x C$, is activated upon testosterone treatment in devel- oping swords and gonopodial rays (Zauner et al., 2003; Offen et al., 2008). In contrast, the gene network is only activated very weakly in platyfish in response to testosterone, suggesting that evolutionary changes in the regulation of the fgfr $1 / m s x C$ network could have caused sword loss in platyfish (Offen et al., 2008).

As candidate genes are chosen based on previous knowledge about their function, only a subset of the genes required during sword and gonopodium development is likely to be identified through candidate strategies. Furthermore, even apparently compelling candidate genes, such as $\mathrm{fgf}_{2} 4$ and fgf $20 a$, with demonstrated roles during fin regeneration or pectoral fin development in zebrafish (Fischer et al., 2003; Whitehead et al., 2005) have turned out not to be expressed during Xiphophorus sword development (Offen et al., 2008). It is, therefore, essential to bypass the limitations of candidate approaches and employ alternative techniques. Microarray experiments and large-scale sequencing of cDNAs have uncovered a collection of genes expressed in the regenerating caudal fin of zebrafish and medaka (Katogi et al., 2004; Schebesta et al., 2006; Nishidate et al., 2007). Since Xiphophorus-specific microarrays are not yet available, we have employed suppression subtractive hybridisation (SSH) (Diatchenko et al, 1996) as an unbiased alternative to identify genes involved in sword and gonopodium development. SSH allows one to detect differences in the abundance of individual transcripts between two transcriptomes, e.g., those of different tissues or developmental stages. This technique has been successfully applied to identify genes differently regulated in caudal fin regeneration (Padhi et al., 2004). We have constructed an SSH library with the aim to detect genes that are differentially expressed in testosterone-induced, developing swords and gonopodia, as compared to juvenile fins prior to induction, and have identified more than 100 of these by sequencing. Gene expression analysis for a subset of genes confirmed their up-regulation during fin metamorphosis and caudal fin regeneration.

\section{RESULTS \\ Construction of a Suppression Subtractive Hybridisation Library From $\boldsymbol{X}$ helleri}

To identify genes that are differentially expressed upon the initiation of sword and gonopodium development from juvenile fins without $a b$ initio assumptions regarding gene function or identity, we employed a suppression subtractive hybridisation (SSH) scheme. We induced sword and gonopodium development in caudal and anal fins, respectively, of immature $X$. helleri with 17- $\alpha$-methyltestosterone with the objective (1) to allow both for the simultaneous generation of large numbers of experimental animals required for tissue isolation and (2) for a precisely timed induction of both processes. Because sword and gonopodium development are induced by increasing testosterone levels in both sexes and fin morphology after metamorphosis is very similar in the two sexes (Grobstein, 1942; Dzwillo, 1964; Zander and Dzwillo, 1969; Ogino et al., 2004), we reasoned that testosterone treatment induces the same genes that act during normal metamorphosis of these fins and independent of the individual animal's sex. To produce the SSH library, we pooled cDNAs from caudal and anal fins that had been treated with testosterone for $1,2,4$, or 5 days, and used untreated fins to collect transcripts before testosterone treatment. Based upon the timecourse of changes in fin morphology, we reasoned that direct targets of testosterone-induced signalling should be activated within the first two days, whereas at 4 and 5 days of treatment genes should be induced that are more downstream and controlled indirectly by testosterone signalling. Because developing swords and gonopodia are thought to modify the activity of parts of the same gene regulatory networks (Zauner et al., 2003; Offen et al, 2008), both tissues from both fins were pooled to increase the starting material. We employed a PCR-based SSH approach (Diatchenko et al., 1996) to enrich for cDNAs that are more abundant in the cDNA pool derived from testosterone-induced swords and gonopodia. These cDNAs are likely to represent genes specifically up-regulated in developing swords and go- 
TABLE 1. Genes With Known Functions That Show Similarity to Identified $X$. helleri Sequences

Housekeeping genes

1. $16 \mathrm{~S}$ ribosomal RNA $(2 \times)$

2. 28 S ribosomal RNA

3. Abhydrolase domain containing 12

4. ATP synthase, $\mathrm{H}+$ transporting, mitochondrial Fo complex, subunit C3

5. ATPase synthase protein 9

6. ATPase, $\mathrm{H}+$ transporting, lysosomal accessory protein 2

7. Cytochrome c oxidase subunit $I(2 x)$

8. Cytochrome $\mathrm{c}$ oxidase subunit II

9. Deoxyhypusine hydroxylase/monooxygenase

10. Elongation factor $1 \alpha$

11. Eukaryotic translation elongation factor 2

12. Histone 3B

13. Integral membrane protein $2 B$

14. kaa190 solute carrier family 25 member 5

15. Mitochondrial ATP synthase $\mathrm{H}+$ transporting complex 1 delta subunit

16. 40S Ribosomal protein $S 2(3 \times)$

17, 40S Ribosomal protein $\mathrm{S} 3 \mathrm{a}$

18. 40S Ribosomal protein $\mathrm{S5}$

19. 40S Ribosomal protein S7

20. 40 S Ribosomal protein $S 8$

21. 40S Ribosomal protein $S 9$

22. 40S Ribosomal protein $S 11$

23. 40S Ribosomal protein S13

24. 40S Ribosomal protein $S 14$, transcript variant 1

25. 40S Ribosomal protein S16 ( $2 \times)$

26. 40S Ribosomal protein $\mathrm{S} 17$

27. 40S Ribosomal protein $\$ 19$

28. 40S Ribosomal protein S20 ( $2 \times)$

29. 40S Ribosomal protein $\$ 27$

30. 40S Ribosomal protein S27a

31. 60S Ribosomal protein L3

32. 60S Ribosomal protein L4 $(2 \times)$

33. 60 S Ribosomal protein L5

34. 60 S Ribosomal protein L6

35. 60 S Ribosomal protein $\mathrm{L} 7$

36. 60S Ribosomal protein L7a (2X)

37. 60S Ribosomal protein L9

38. 60S Ribosomal protein L10

39. 60S Ribosomal protein L10a $(2 \times)$

40. 60S Ribosomal protein L11.

41. 60S Ribosomal protein L13

42. 60S Ribosomal protein L13a

43. 60 S Ribosomal protein L14

44. 60S Ribosomal protein L18

45. 60S Ribosomal protein $\mathrm{L} 18 \mathrm{a}$

46. 60 S Ribosomal protein L23a

47. 60 S Ribosomal protein L27

48. 60S Ribosomal protein L31

49. 60S Ribosomal protein L35a

50. 60S Ribosomal protein L35b

51. 60S Ribosomal protein L36

52. 60S Ribosomal protein L37a

53. 60S Ribosomal protein L38

54. Succinate-CoA ligase, alpha subunit

55. Tomm 40

56. Transglutaminase 2

57. Translation factor suil-like

58. Translation initiation factor $4 \mathrm{E}$ transporter

59. Ubiquitin
Structure and cytoskeleton

60. Actin-related protein 3

61. Alpha-tubulin

62. Beta actin $(6 \times)$

63. Tubulin beta-1 chain

64. BsR19 keratin

65 . type 1 collagen alpha $1(3 \times)$

66 . type 1 collagen alpha 2

67 . Collagen, type $X$, alpha 1

68. Cytokeratin

69. Keratin $15(2 \times)$

70. Keratin 5 protein, transcript variant 1

71. Keratin 5 protein, transcript variant 2

72. Keratin K10

73. MID1 interacting protein 1

74. Osteonectin

75. type V/XI collagen pro-alpha 1

76. type I Keratin isoform 1

77. type II keratin

78. type II keratin E3

Stress and immune response

79. Amet protein

80 . Ferritin heavy chain subunit

81. B2-microglobulin

82. Peroxiredoxin $4(2 \times)$

Signalling and transcription factors

83. C-fos

84. 14-3-3, a protein

85. Calmodulin $(2 \times)$

86. Cystatin B

87. Dual specificity phosphatase 1

88. Kruppel-like factor $2 \mathrm{a}$

89. Kruppel-like factor $2 \mathrm{~b}(2 \times)$

90. M-Calpain

91. Protein phosphatase 1, catalytic subunit, beta isoform

92. Receptor for activated protein kinase C (RACK1) $(2 \times)$

93. S100-like

94. Thymosin beta a-like

Other

95. Cysteine-rich protein 2

96. DEAD (Asp-Glu-Ala-Asp) box polypeptide 5

97. Hemoglobin beta-A chain

98. Human DNA sequence from clone RP5-1107C24 on chromosome 20

99. Protein LOC553453

100. Setenoprotein W2a

101. Sperm plasma glycoprotein 120

102. Splicing factor $3 \mathrm{~b}$, subunit 1

103. Translationally controlled tumor protein-like

104. Tetraodon nigroviridis full-length cDNA

105. Tetraodon nigroviridis full-length cDNA

106. Tetraodon nigroviridis full-length cDNA 
nopodia and are putative candidates to function in sword and gonopodium development.

To test the efficiency of the subtractive hybridisation, a fragment of gapdh, a ubiquitously expressed gene, was amplified from the pool derived from testosterone-induced fins before and after subtractive hybridisation was performed. We examined the presence of gapdh-specific PCR-products after different numbers of PCR cycles. A gapdh PCR-product was obtained 5 cycles later after subtractive hybridisation was performed, demonstrating that the amount of gapdh transcript thought to be present in fins before and after treatment was successfully reduced by SSH (Fig. 1E). The subtracted cDNAs were used to construct an SSH library and 406 clones were chosen for sequencing (Fig. 1F). The average insert size of the chosen clones was $\sim 400$ base pairs (bp), with an individual insert size between 100 and $700 \mathrm{bp}$. A more detailed analysis of the 406 sequences reduced the sequence data to 201 contigs and independent sequences (Fig. 1F). A contig or sequence was considered to be independent if it showed no significant overlap with other contigs and sequences. One hundred twenty-eight out of these 201 contigs/sequences $(-64 \%)$ showed reliable similarity (exhibiting E-values of $e^{-15}$ or less) to known genes using the Blast algorithm (Altschul et al., 1990) (Fig. 1F). The remaining 73 sequences consisted of repetitive elements $(6 / 8 \%)$, vectoror poly-A-sequences $(5 / 7 \%)$, and sequences without reliable blast hits $(62 / 85 \%)$, likely to be UTR sequences. From the 128 sequences with a significant blast hit, $27(53 \%)$ showed reliable similarity to ribosomal or other housekeeping genes, 27 (21\%) to components of the cytoskeleton and structural genes, $16(13 \%)$ to transcription factors or genes involved in signal transduction, 5 (4\%) to known stress and immune response genes, and 12 $(9 \%)$ to genes with other or unknown function (Fig. 1F and Table 1). Some of these sequences, although independent from each other, showed similarity to the same gene and might just represent different parts of it (Table 1).

\section{SSH-Enriched Genes Are Expressed in Developing Swords and Gonopodia}

In trying to better understand the molecular mechanisms of sword and gonopodium development, we were strongly interested in transcription factors and signalling pathways that might control these processes. Therefore, out of the class of 16 genes that showed similarities to transcription factor genes or genes involved in signal transduction, we chose seven clones with similarity to $14.3 .3 a$, c-fos, dual specific phosphatase1 (dusp1), receptor for activated protein kinase $C$ (rack1), krueppel-like factor 2 (klf2), $\mathrm{m}$ calpain, and thymosin $\beta$-like (tms $\beta$-like) for further analysis. As an assay independent of the SSH procedure, we confirmed the expression of the selected genes in developing gonopodia and swords by nonquantitative reverse-transcribed (RT)PCR in fin tissue from fish treated with testosterone for 2 and 5 days. Two days of treatment represented the stage of primary response to testosterone (possible direct targets), whereas 5 days represented the stage of secondary response to testosterone (possible indirect targets). All genes were expressed in caudal and anal fins after 2 and 5 days of testosterone treatment (dt) as well as in untreated control fins (Fig. 2). The RT-PCR experiment confirmed that all genes are indeed expressed in developing swords and gonopodia and are not an artefact created by the method itself.

\section{Expression of SSH-Enriched Genes During Sword Development}

Next we determined whether these genes are differentially expressed (1) in developing sword rays, compared to control fin rays, and (2) in sword rays after testosterone treatment for a range of time periods. We induced sword development in juvenile fish with $17-\alpha$ methyltestosterone and performed expression analysis on caudal fins by whole mount in situ hybridisation after 2 and 5 days. Given that some of the isolated cDNA clones were too short to yield antisense transcripts suitable for expression analysis by in situ hybridisation, we produced a full-length, nonsubtracted cDNA library from induced swords and gonopodia after $1,2,4$, and

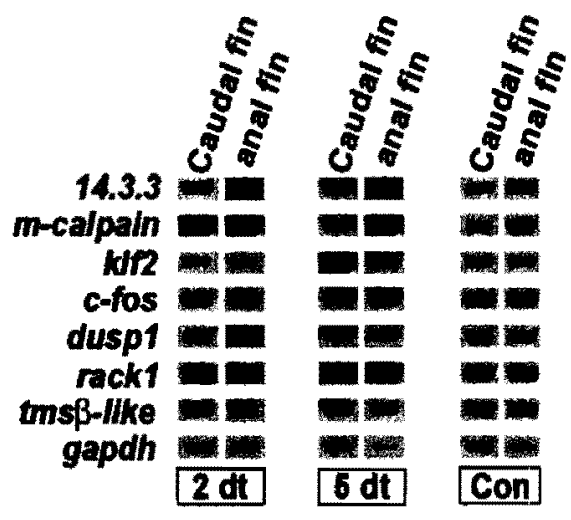

Fig. 2. Expression of genes obtained by SSH. Seven genes from the "signalling and transcription factor" category were chosen and their expression was confirmed by RT.PCR. All seven genes are expressed in testosterone-treated caudal and anal fins after 2 and 5 days of treatment, as well as in untreated (control) ins. gapdh was used as positive control.

$5 \mathrm{dt}$, which we used to isolate cDNA fragments of sufficient length.

The sword is formed by the ventral caudal fin rays $V 7-V 10$, based on Dzwillo's nomenclature for the caudal fin rays of $X$. helleri (Dzwillo, 1964). After $2 \mathrm{dt}$, rack1 was expressed at similar levels throughout the whole caudal fin with no obvious differences between sword and non-sword rays and at the same overall levels as in control fins (Fig. 3A, C). In contrast, after $5 \mathrm{dt}$ rack 1 was strongly up-regulated in the distal tips of the sword forming rays V8-V9 compared to nonsword rays in the median or dorsal caudal fin (Fig. 3B, B'). rack1 expression levels in V7 were similar to nonsword rays and no outgrowth of $\mathrm{V7}$ was yet visible (Fig. 3B).

klf2 was expressed similarly to rack1. After $2 \mathrm{dt}$, klf 2 expression was detected at basal levels in all caudal fin rays (Fig. 3D), yet at $5 \mathrm{dt} k l f 2$ is more strongly expressed in ventral sword rays V7-V10 than in non-sword fin rays (Fig. 3E, E'). klf2 expression appears to overlap with that of rack1 (compare Figs. 3B' and E'). In control fins, $k l f 2$ is equally expressed at low levels in sword rays and the remaining fin rays (Fig. 3F).

$t m s \beta$-like transcription did not differ between ventral, median, and dorsal caudal fin rays after $2 \mathrm{dt}$ (Fig. 3G). In contrast, after $5 \mathrm{dt} t m s \beta$-like is clearly up-regulated in the sword region and seems to enclose the distal tip of the sword rays (Fig. $3 \mathrm{H}, \mathrm{H}^{\prime}$ ). 

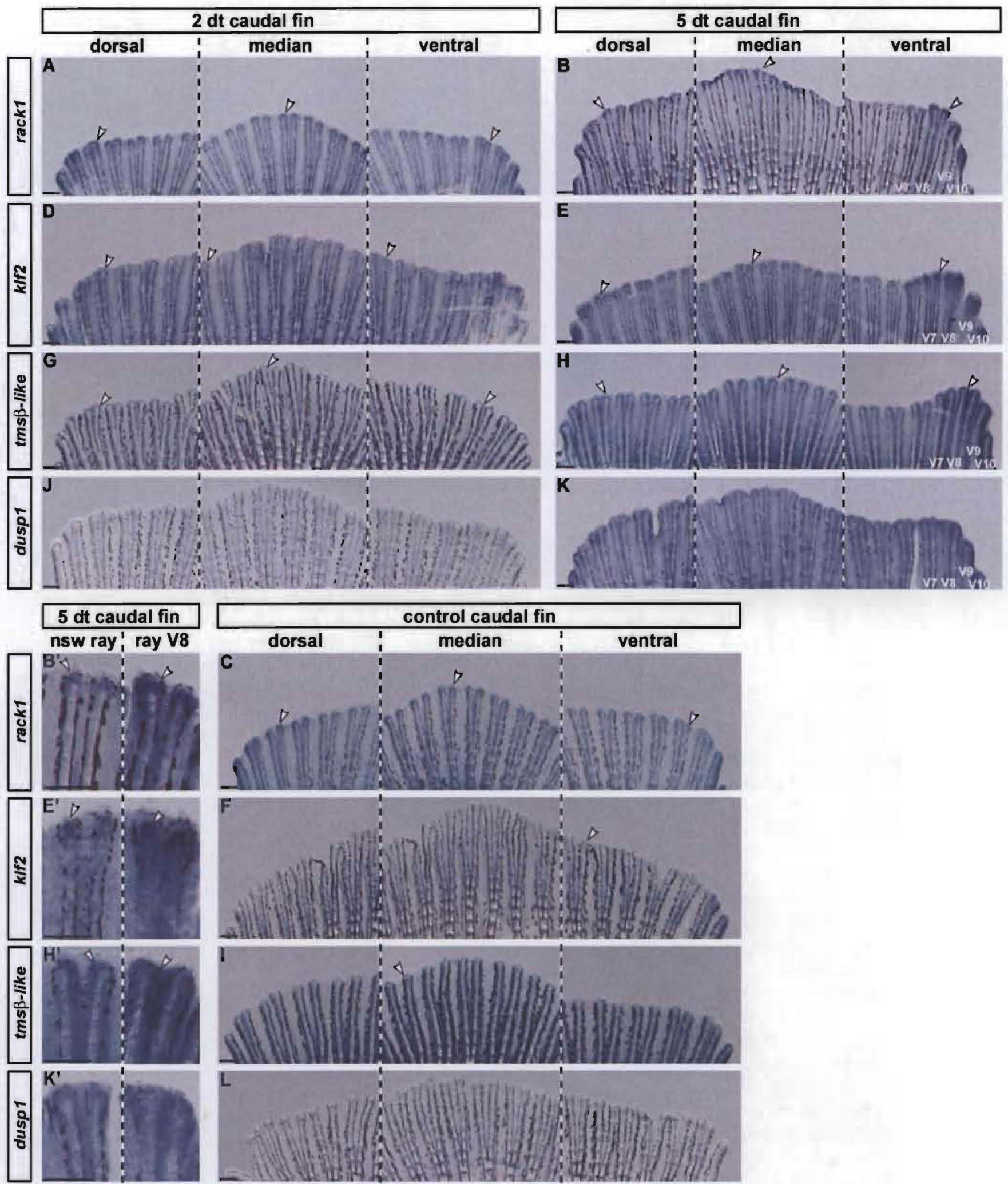

Fig. 3. Regulation of SSH-enriched genes in developing swords. A-L: rack1 is up-regulated in growing sword rays, compared to non-sword (nsw) rays after 5 days of testosterone treatment $(\mathrm{dt})\left(\mathrm{B}, \mathrm{B}^{\prime}\right)$. In caudal fins after $2 \mathrm{dt}(\mathrm{A})$ and in control fins, rack $1(C)$ is expressed at basal levels in all fin rays. Basal expression of klf2 can also be detected in caudal fins after $2 \mathrm{dt}(\mathrm{D})$ and control fins (F). After $5 \mathrm{dt}$, klf2 is transcribed at higher levels in the sword rays compared to $n s w$ rays $\left(E, E^{\prime}\right)$. tms $\beta$-like is more strongly expressed in the developing sword compared to the rest of the caudal fin $\left(H_{1}, H^{\prime}\right)$, whereas in caudal fins after $2 \mathrm{dt}(\mathrm{G})$ and in control fins $(\mathrm{I})$, expression levels of tms $\beta$-like are similar between sword and nsw rays. dusp 1 expression could not be detected in either testosterone treated fins after $2 \mathrm{dt}(\mathrm{J})$ or $5 \mathrm{dt}(\mathrm{K})$, nor in control fins (L). White arrowheads indicate gene expression. $\mathrm{V}$, ventral ray. $5 \mathrm{dt}: \mathrm{n}=5$ for rack1, klf2, and tms $\beta$-like; $n=10$ for $d u s p 1 ; 2 \mathrm{dt}$ and control fins: $n=4$ for every probe. Scale bars $=200 \mu \mathrm{m}$. 


\section{$2 \mathrm{dt}$ anal fins}
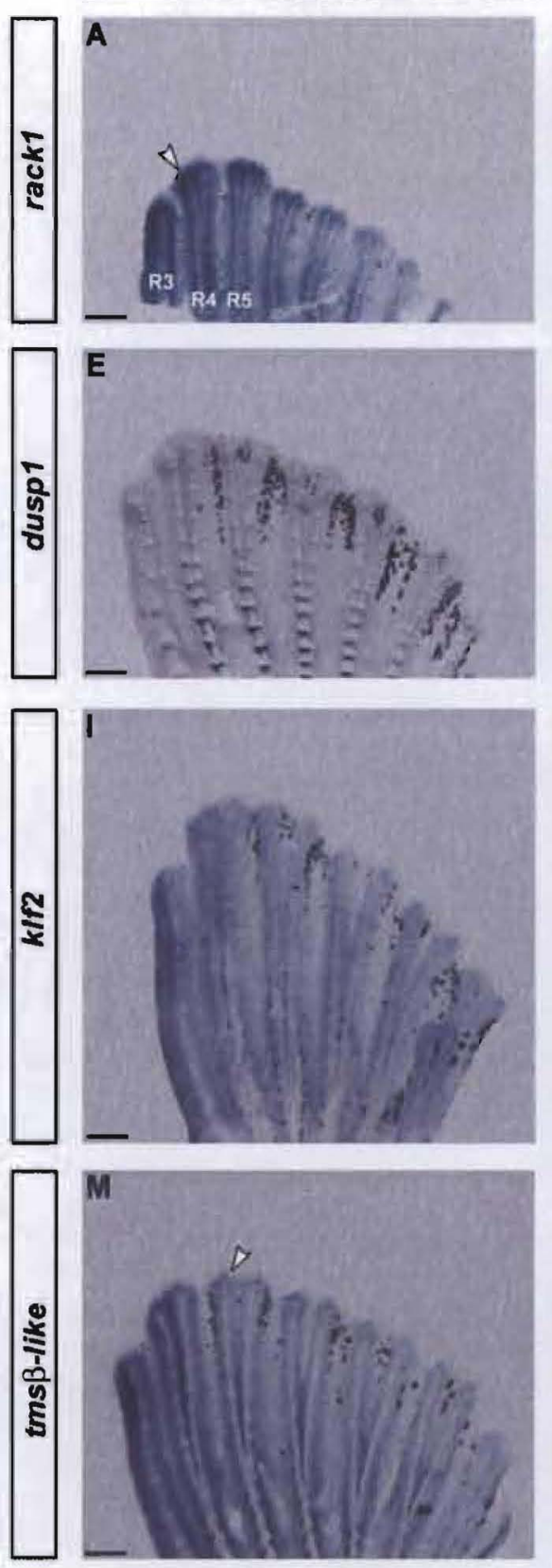
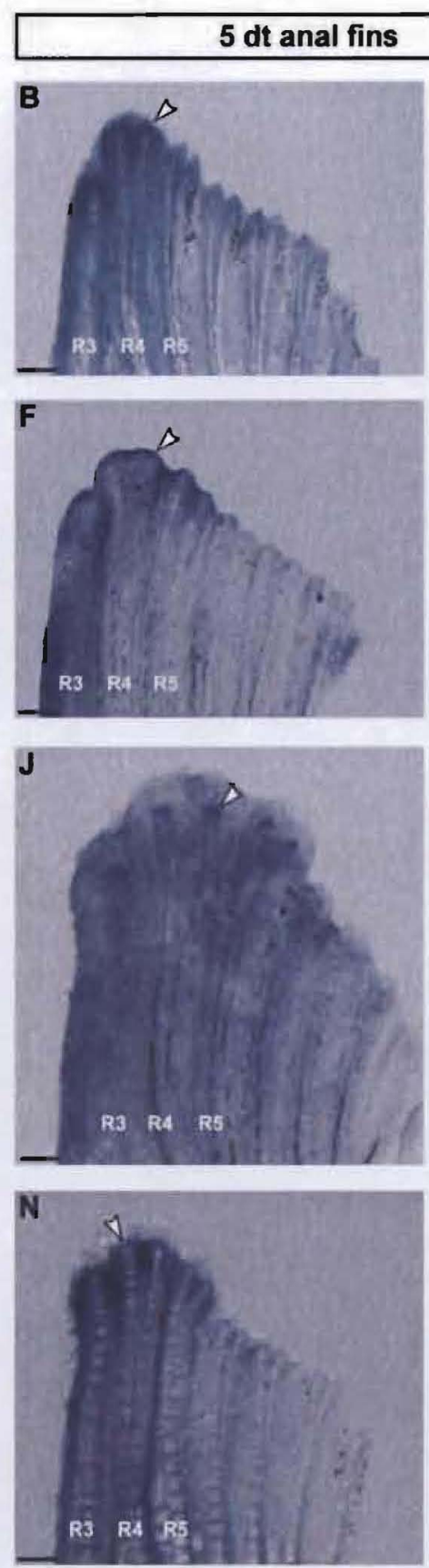
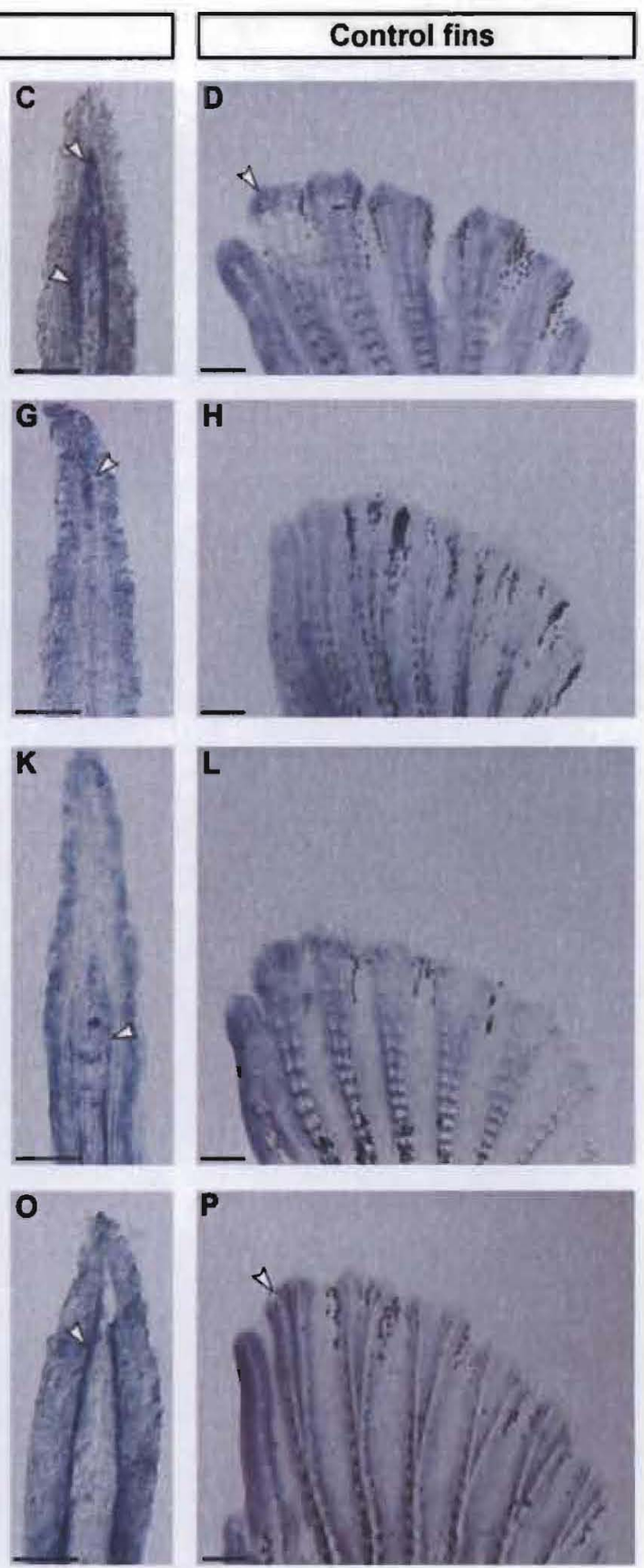

Fig. 4. Regulation of SSH-derived genes in developing gonopodia. A-P: rack1, dusp1, klf2, and tms 3 -like are up-regulated in the 3-4-5 complex of developing gonopodia. The anal fin rays 3,4 , and 5 show higher levels of rack1 (B), duspl (F), klf2 (J), and tms $\beta$-like (N) transcripts after 5 dt than the remaining anal fin rays. A more detailed analysis of the expression pattern of the four genes in tissue sections revealed that dusp 1 expression is localised to the distal mesenchyme (G), whereas klf2 is transcribed in the lateral mesenchyme (K). rack1 expression can be found in both mesenchymal compartments (C). tms $\beta$-like is expressed in the basal layer of the epidermis (O). After $2 \mathrm{dt}$, rack 1 is also clearly up-regulated in the anal fin rays 3,4 , and 5 (A). tms $\beta$-like transcript levels appear slightly higher in the 3-4-5 complex after $2 \mathrm{dt}(\mathbf{M})$. dusp1 (E) and kIf2 (I) expression is not detectable by in situ hybridisation in anal fins after $2 \mathrm{dt}$. In control fins, rack1 (D) and tms $\beta$-like (P) are transcribed at basal levels in all fin rays, whereas dusp1 (H) and klf2 (L) expression cannot be detected. White arrowheads, gene expression. R, anal fin ray. $5 \mathrm{dt}: \mathrm{n}=5$ for every probe; $2 \mathrm{dt}: \mathrm{n}=4$ for every probe; control fins: $n=3$ for every probe. Scale bars = (A, B, D, E, F, H, I, J, L, M, N, P) $200 \mu \mathrm{m},(\mathrm{C}, \mathrm{G}, \mathrm{K}, \mathrm{O}) 100 \mu \mathrm{m}$.

tms $\beta$-like is also expressed in nonsword rays, although at lower levels. In control fins, only weak expression of $t m s \beta$-like could be detected in some fin rays (Fig. 3I).

dusp1 expression could not be detected after 2 and $5 \mathrm{dt}$ even after pro- longed staining (Fig. 3J, $\mathrm{K}, \mathrm{K}$ ) or in untreated fins (Fig. 3L). 14.3.3a showed ubiquitous expression in the whole caudal fin with no obvious differences between sword and non-sword rays. No distinct expression pattern could be obtained for $c$-fos and $m$-calpain (data not shown). In summary, expression analysis showed that rack1, klf2, and tms $\beta$-like are strongly up-regulated in sword rays during sword outgrowth at $5 \mathrm{dt}$. Phylogenetic data used for the annotation of rack 1, dusp 1, klf2, and tms $\beta$-like are available upon request. 


\section{Specific Expression of SSH- Enriched Genes in Rays Forming the Gonopodium}

In order to examine the idea that the molecular networks that are activated during sword development are also active in the gonopodium, we analysed the expression pattern of these genes in the metamorphosing anal fin. The gonopodium develops from the anal fin rays 3 , 4 , and 5, the so-called 3-4-5 complex (Langer, 1913). rack1 is up-regulated in the 3-4-5 complex after $2 \mathrm{dt}$ (Fig. 4A) and $5 \mathrm{dt}$ (Fig. 4B) when compared to the remaining anal fin rays. Up-regulation of rack1, therefore, occurs earlier in the gonopodial rays than in rays of the developing sword. An analysis of rack1 expression on tissue section revealed that both the distal and the lateral compartment of the fin ray mesenchyme express rack1 (Fig. 4C). In untreated anal fins, rack1 is expressed at basal levels in all fin rays (Fig. 4D). Expression of dusp1 could not be detected in anal fins at $2 \mathrm{dt}$ (Fig. 4E). After $5 \mathrm{dt}$, however, duspl is strongly expressed in the distal mesenchyme of the 3-4-5 complex (Fig. 4F, G), but not in any other anal fin rays or in control fins (Fig. 4F, H). Thus, differential expression of duspl could be detected in growing gonopodia, but not in swords (compare Figs. 3K and 4F). The spatio-temporal expression pattern of $k l f 2$ in developing gonopodia is comparable to that of swords. After $2 \mathrm{dt}$, the klf 2 transcript could not be detected in the anal fin (Fig. 4I), but after 5 days of testosterone treatment klf2 was exclusively up-regulated in the 3-4-5 complex (Fig. 4J). klf 2 expression was located to the lateral mesenchyme (Fig. 4K) and, therefore, partially overlapping with rack1 expression (Fig. 4C). No expression of klf 2 could be detected in control fins (Fig. 4L). tms $\beta$-like showed comparable expression in the 3-4-5 complex and the remaining anal fin rays after 2 dt (Fig. 4M). As in induced swords, tms $\beta$-like is up-regulated in the $3-4-5$ complex (Fig. 4N). Unlike the other genes, tms $\beta$-like is not expressed in the mesenchyme, but in the adjacent basal cell layer of the fin ray epidermis (Fig. 40). In some samples, $t m s \beta$-like showed slightly stronger expression in rays 3 and 4 (Fig. 4N). Control fins expressed $t m s \beta$-like at a basal level in all fin rays (Fig. 4P). 14.3.3a was also ubiquitously expressed as in the sword, and no distinct expression pattern could be detected for $c$-fos and $m$-calpain (data not shown).

Together, these results show that while rack1, dusp1, klf2, and tms $\beta$-like are all ultimately up-regulated in the 3-4-5 complex during gonopodial outgrowth at $5 \mathrm{dt}$, clear differences in gene regulation are also obvious. Transcription rates of rack1 are up-regulated much faster in the anal than in the caudal fin upon testosterone induction, while strong $d u$ sp 1 expression appears to be specific to the developing gonopodial rays, but is mainly absent from sword rays.

\section{SSH-Derived Genes Are Expressed in Regenerating Swords}

The repertoire of signalling pathways controlling fin development often is also used again during regeneration of amputated fin tissue (reviewed in Iovine, 2007), a process in which fin rays exhibit accelerated growth similar to that experienced during adult fin metamorphosis. To examine whether the set of genes characterised during sword and gonopodium development was expressed during regeneration, we amputated the caudal fins of male swordtails and allowed them to regenerate for 4 days. Gene expression was then analysed by in situ hybridisation both on whole fins and on longitudinal sections, which allows the analysis of gene expression at cellular resolution and overcomes the limitations with the sensitivity of the in situ hybridization technique on whole fins (Smith et al., 2008).

All four genes, rack1, dusp1, klf2, and tms $\beta$-like, were also expressed during fin regeneration. rack 1 was upregulated in non-sword (Fig. $5 \mathrm{~A}$ ) and sword rays (Fig. 5B). Due to the larger size of the sword ray blastemata, the expression domain of rack1 in sword rays is clearly wider. rack1-expressing cells are found in the lateral compartments of the blastema, such as differentiating scleroblasts, and the distal region of the median mesenchyme (Fig. 5C). dusp 1 is expressed in a caplike pattern in the distal tip of nonsword (Fig. 5D) and sword rays (Fig. $5 \mathrm{E}$ ). Fin sections revealed $d u s p 1$ to be expressed in the distal region of the median blastema (Fig. 5F). Thus both $d u s p 1$ and rack1 are activated in the distal part of the blastema during fin regeneration (compare Fig. $5 \mathrm{C}$ and $\mathrm{F}$ ). klf2 shows an expression pattern in non-sword (Fig. 5G) and sword rays (Fig. 5H). Unlike rack1, klf2 is only expressed in proximal lateral mesenchymal cells, likely to be scleroblasts, but not in the distal blastema (Fig. 5I). tms $\beta$-like is expressed at similar levels in normal (Fig. 5J) and sword rays (Fig. 5K) where it is restricted to the basal epidermal layer that covers the mesenchymal blastema (Fig. 5L).

Judging from these analyses, it is apparent that all four genes are expressed during fin development (Figs. 3 and 4) as well as sword regeneration (Fig. 5) and thus are likely to fulfill similar roles in promoting the growth and regeneration of fin rays.

\section{DISCUSSION}

The molecular mechanisms controlling the development of the sword, a sexually selected trait in the genus $X i$. phophorus, have been targeted in previous studies in which candidate gene approaches were employed that focused on genes with known expression and functions during zebrafish fin regeneration (Zauner et al., 2003; Offen et al., 2008). As candidate genes were selected on the basis of prior information about their expression or function in other contexts, genes with unexpected functions or novel genes were not identified by this approach. In this study, we employed suppression subtractive hybridisation (SSH) to bypass this problem (Diatchenko et al., 1996). We successfully identified genes that are differentially expressed in developing swords and gonopodia compared to juvenile fins before metamorphosis.

\section{Genes Up-Regulated During Xiphophorus Fin Metamorphosis Can Be Identified by Subtractive Hybridisation}

In total, we identified 201 independent sequences, or contigs, of which 128 showed significant similarities to sequences in public databases. To our knowledge, this study provides the first collection of expressed sequence tags (ESTs) from developing swords and gonopodia. A large fraction of sequences (73) showed no significant similarity to 

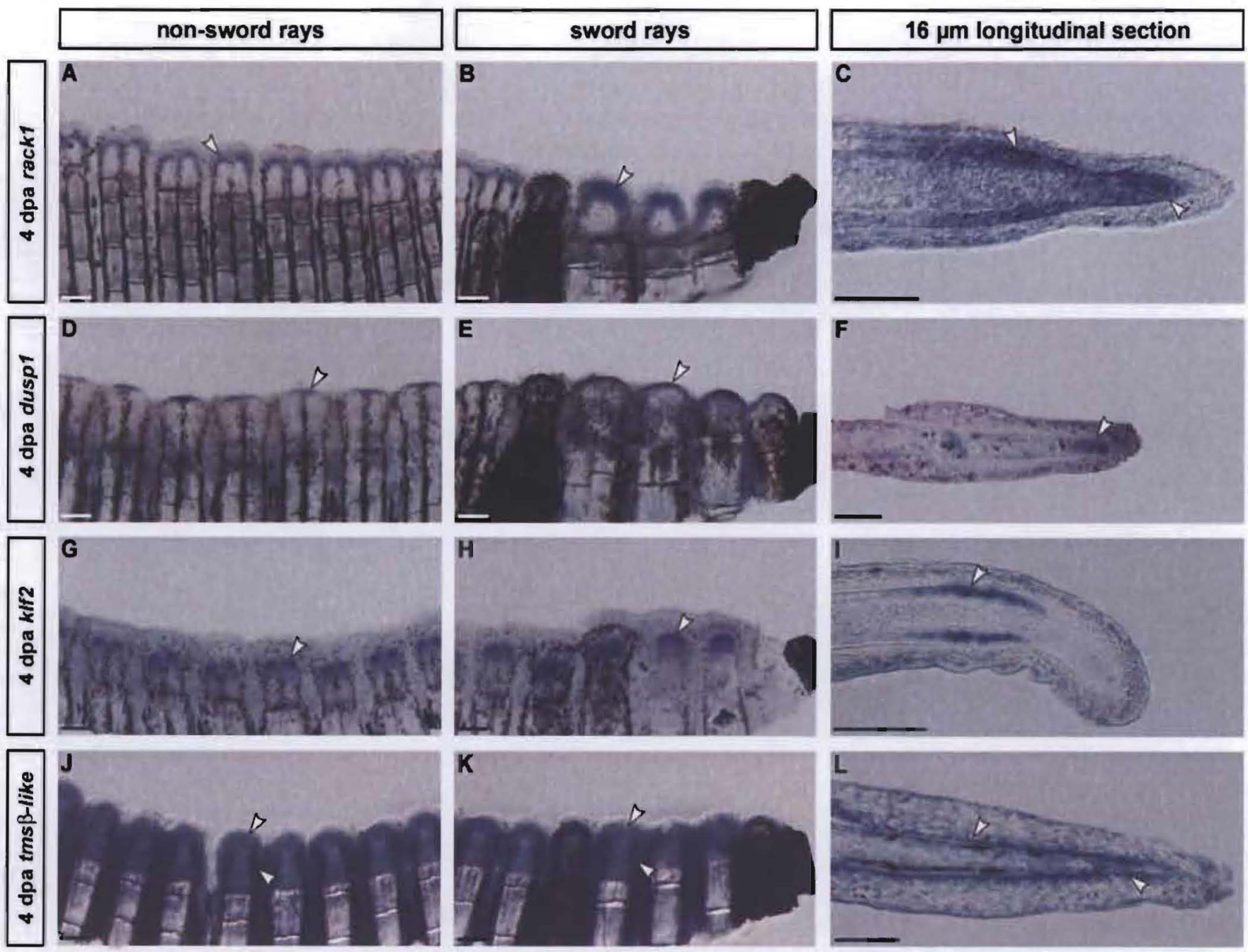

Fig. 5.

Fig. 5. Expression of SSH-derived genes in regenerating caudal fins. A-L: Expression of rack1, dusp 1, klf2, and tms $\beta$-like in regenerating caudal fins. All genes are expressed at similar levels in non-sword (A, D, G, J) and sword rays (B, E, H, K). rack1 expression is detected in the distal medial region of the blastema as well as in more proximal and lateral regions, where it might overlap with scleroblasts (C). dusp1 is expressed in the distal part of the blastema, where it overlaps with rack1 expression (F). k/f2 expression overlaps with that of rack1 in the lateral mesenchymal compartment that contains newly formed scleroblasts (i). tms $\beta$ like is expressed in the epidermis, specifically in the basal epidermal layer (L). White arrowheads, gene expression. dpa, days post amputation. $\mathrm{n}=$ 4 for every probe, except kif2: $n=7$. Scale bars = $(A, B, D, E, G, H, J, K) 200 \mu \mathrm{m},(C, F, I, L) 100 \mu \mathrm{m}$.

Fig. 6. Summary of the expression pattems of rack1, dusp1, kit2, and tms $\beta-$ like. Summary of expression pattems of rack1, dusp1, klf2, and tms $\beta$-like in growing gonopodial rays of $X$. helleri. rack1 expression partly overlaps with that of dusp1 in the distal mesenchyme and with that of kff2 in the lateral mesenchyme (e.g., newly formed scleroblasts). tms 3 -like is expressed in the basal layer of the epidermis. Expression is similar in regenerating fin rays ( 4 days post-amputation), in which the mesenchymal domains described above are part of a blasterna. BL, basal epidermal layer; DM, distal mesenchyme; $E$, epidermis; L, lepidotrichia; LM, lateral mesenchyme; $M$, mesenchyme.

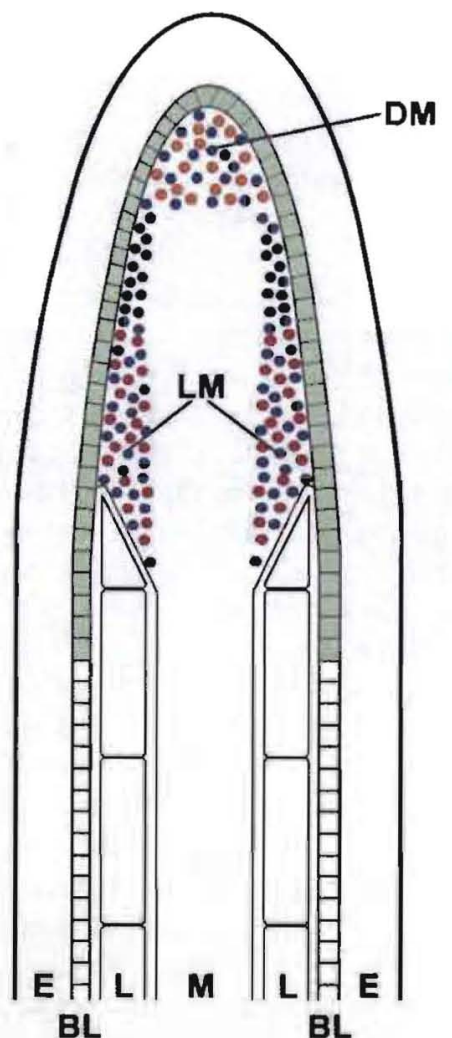

dusp1 expression

klf2 expression

rack1 expression

tms $\beta$-like expression

Fig. 6. 
sequences in the database. These sequences could represent untranslated regions (UTRs) or weakly conserved parts of the coding region.

A subset of 15 transcripts was represented by multiple (2-6), independent sequences, as can be expected for abundant transcripts, given that the average insert length of SSH clones is $400 \mathrm{bp}$. Housekeeping genes, but also genes encoding structural components inside and outside the cell, make up $75 \%$ of our EST pool, In line with our findings and the observation that genes required for fin development are re-used during regeneration, these transcripts were also quite abundant in an SSH library of regenerating fins (Padhi et al., 2004). In theory, one would expect that genes required for cellular maintenance should be eliminated by this method. However, transcripts of housekeeping genes are probably more abundant in growing fin rays, due to a higher demand for energy or protein synthesis in growing tissue and will be only partly removed by SSH. Genes encoding for structural components, like keratins and collagens, have been shown to be more strongly expressed in regenerating fins of zebrafish and medaka than in uninjured fins (Katogi et al., 2004; Padhi et al., 2004; Schebesta et al., 2006; Nishidate et al., 2007). They are likely to participate in the re-structuring of new fin tissue, since keratins are the major structural proteins in epithelial tissues and collagens are part of the lepidotrichia and actinotrichia (Bechara et al., 2000; Yamada et al, 2002).

Approximately half of the obtained genes that code for transcription factors or are involved in cell signalling were also found to be expressed in regenerating caudal fins of zebrafish and medaka (Katogi et al., 2004; Padhi et al., 2004; Schebesta et al, 2006). This is not surprising, since both sword development and fin regeneration are characterised by elevated outgrowth of fin rays, which seems to be controlled by a conserved genetic network (reviewed in Iovine, 2007). However, it will be highly interesting to evaluate those genes that are strongly expressed in sword or gonopodial rays but less so in regenerating caudal fins, as they may be involved in the downstream response to testosterone signalling.
Differential Expression of SSH Candidates in Developing Swords and Gonopodia and Regenerating Caudal Fins

Our gene expression analyses of seven clones from the transcription factor/cell signalling category showed that the genes rack1, dusp 1, klf2, and tms $\beta$-like are differentially expressed in developing swords and/or gonopodia compared to juvenile fins before testosterone-induced metamorphosis. For two genes with similarity to $c$-fos and m-calpain, we failed to show any distinct expression in developing swords and gonopodia or regenerating caudal fins. It is likely that both genes are expressed at rather low levels that escape detection by in situ hybridisation, as RT-PCR clearly showed that the two genes are transcribed in developing swords and gonopodia.

Interestingly, all genes, except rack1, are exclusively expressed at later stages of testosterone treatment, when outgrowth of sword and gonopodial fin rays becomes morphologically apparent. In induced gonopodia, but not in induced swords, rack1 transcription, was activated before outgrowth started.

It remains elusive why the SSH approach mainly obtained genes that become active during the outgrowth phase rather than earlier and as an immediate response to androgen signalling. One possibility is that cDNAs derived from genes that are directly regulated by androgen receptors were only present in low copy number within the SSH pool. If true, direct targets might be detected by sequencing a larger number of clones. Another possibility would be that the levels of transcriptional activation of direct targets are below the detection limits of the in situ hybridization technique. In the future, this may be possible to test through more sensitive quantitative methods, such as reverse-transcribed (RT)-PCR of candidate genes.

Even though the number of identified genes is strongly correlated with the number of sequenced clones, the SSH remains a valuable technique, since the number of alternative methods is limited for a non-model organism like $X$, helleri. Species-specific microarrays are not yet available and an efficient detection of differentially expressed genes by a mass sequencing approach would require more advanced resources such as next generation DNA sequencing (Hornshøj et al., 2009). Another technique, differential display RT-PCR (DDRT-PCR), cannot be used efficiently in Xiphophorus. DDRTPCR selectively amplifies small fragments from the 3 -UTR of ideally all cDNAs to produce a gene expression profile that can be compared between two samples (Liang et al., 1992). For $X$. helleri, however, the genomic and EST information currently is still insufficient to allow a fast and reliable identification of these sequences.

After 2 days of testosterone (dt) treatment, rack 1 transcription is already increased in the anal fin, before the 3-4-5 complex starts to grow out, and might therefore act in the induction of fin growth. Interestingly, the genes we identified are expressed in all of the compartments relevant for regeneration, i.e, the distal median blastema, basal layer of the epidermis, and scleroblast-forming lateral blastema. Similar expression domains are present in the mesenchyme and basal epithelial layer of growing fins. We summarize gene expression in growing and regenerating fin rays in Figure 6 . All three compartments have a distinct role in promoting fin ray growth. The lateral mesenchymal compartment of both developing swords and gonopodia after $5 \mathrm{dt}$ and regenerating caudal fins expresses rackl and klf2 (Fig. 6). Studies in regenerating fins showed that the lateral compartment of the mesenchyme contains newly formed scleroblasts that align along the basal epidermal layer to produce new hemiray segments (Laforest et al., 1998; Quint et al., 2002). Scleroblast expression of rack 1 and $k$ lf 2 might indicate a role for both genes in dermal bone formation.

rack1 may be linked to the gene-regulatory network controlling hemiray development or regeneration via Fgf or Bmp signalling. Two lines of evidence support a putative interaction between rack1 and Fgf signalling: First, fgf receptor $1(f g f r 1)$ is up-regulated in developing swords and gonopodia as well as regenerating caudal fins of $X$. helleri. In addition, fgfr 1 is co-expressed with rack1 in scleroblast cells (Offen et al., 2008). Second, rack1 expression is regulated by Fgf signalling in developing chick limb buds (Lu et al., 2001). Rack1 is thought to bind and stabilize activated Protein kinase $\mathrm{C}$ (PKC) and re- 
cruits the kinase to its targets (reviewed in McCahill et al., 2002). Therefore, Fgf signalling both activates PKC and increases Rack1 levels to enhance its activity in the chick limb bud (Lu et al., 2001), rack1 might also act on bone formation via the Bmp signalling pathway. Rack1 has been shown to be required for Bmp2-induced phosphorylation of Smads via the $B m p$ receptor 2 (Zakrzewicz et al., 2007). In regenerating caudal fins of zebrafish, $b m p 2 b$ is expressed in scleroblasts, and both knockdown of Bmp signalling and overexpression of $b m p 2 b$ impairs dermal bone formation (Laforest et al., 1998; Quint et al., 2002; Smith et al., 2006).

Whether dermal bone formation also requires klf2 remains uncertain. Klf2 is a C2/H2 zinc finger transcription factor that can either activate or repress transcription of target genes (reviewed in Atkins and Jain, 2007). Two klf2 paralogs have been described in zebrafish due to the fish-specific genome duplication (Oates et al., 2001). klf2a seems to fulfill the ancestral function of klf 2 in blood vessel development and control of blood pressure, while the function of the second paralog is not known (Oates et al., 2001; Bhattacharya et al., 2005; Lee et al., 2006). The isolated klf2 sequence seems to represent the Xiphophorus $k l f 2 b$ ortholog (data not shown). It will be interesting, therefore, to further analyse whether the expression in scleroblasts of growing or regenerating fin rays is a unique feature of $k l f 2 b$ or if it points towards an ancestral function of klf2 in appendage growth and regeneration. Functional analyses of $k l f 2$ and rack1 in a suitable experimental system, e.g., the regenerating zebrafish caudal fin, will be required to show whether both genes act within the same or in parallel pathways.

dusp1 (also known as MAP kinase phosphatase-1, mkp1) might promote endothelial cell migration (Kinney et al., 2008) in the distal medial mesenchyme. In endothelial cells (EC), dusp1 is activated by Vegf-A and Vegf-E via the Vegf receptor 2, and knockdown of dusp 1 perturbs VEGF-induced EC migration. vegfr 2 is expressed in the distal-most blastema of regenerating caudal fins of zebrafish and inhibition of Vegf signalling showed that angiogenesis is essential for regenerative outgrowth of fin rays (Bayliss et al, 2006). dusp1, therefore, might be involved in regulating the migration of ECs in growing and regenerating fin rays to promote the formation of new blood vessels. As a MAP kinase phosphatase, Duspl is likely to regulate the activity of MAP kinases (Teng et al., 2007; Caunt et al., 2008) that transmit the Vegf signal (Chakroborty et al., 2008; Kinney et al., 2008). Inhibition of Vegf signalling (Bayliss et al, 2006) or knockdown of dusp1 in the zebrafish system will be helpful to validate or reject this hypothesis. Furthermore, functional data will useful to show whether dusp 1 and rack1 fulfill different roles during ray outgrowth or interact with each other. It is unlikely that dusp1 is not expressed in developing sword rays, since its expression was confirmed by RT-PCR and because both growing gonopodia and regenerating swords showed up-regulation of the gene. Rather, we believe that dusp 1 may be expressed in sword rays at levels below the detection limit of the in situ hybridisation technique.

tms $\beta$-like is expressed in the basal epidermal layer, which is thought to act as a signalling center that directs processes such as scleroblast alignment and differentiation of scleroblasts (Laforest et al., 1998; Quint et al., 2002), and cell proliferation by activation of mesenchymal genes like $m s x b$ (Nechiporuk et al., 2002; Poss et al., 2000, 2002 ). $\beta$-thymosins have been shown to promote angiogenesis and accelerate dermal wound healing (Malinda et al., 1997, 1999), apart from its main cellular function as a regulator of actin polymerisation in a subset of developing neurons (Roth et al., 1999). Application of Thymosin $\beta 4$ (Tms $\beta 4$ ) to dermal wounds of rats stimulates migration of endothelial cells (Malinda et al., 1997). Furthermore, a tetrapeptide derived from Tms $\beta 4$ was shown to promote the formation of new blood vessels in subcutaneously injected matrigel plugs soaked with the protein (Grillon et al., 1990; Liu et al., 2003). In addition, exogenous Tms $\beta 4$ can also stimulate the migration of keratinocytes and collagen deposition (Malinda et al., 1999). Therefore, $t m s \beta$-like might assist in the formation of new blood vessels and skeletal elements in growing fin rays. Even though tms $\beta$-like is expressed in the basal epidermal layer (Fig. 6), $\beta$-thymosins have been shown to be secreted into the extracellular compartment
(Huang and Wang, 2001), which would enable $t m s \beta$-like (tms $\beta$ ) to diffuse to target sites in developing fin rays.

We can propose a deliberately tentative model of how the four genes might act during fin ray growth (Fig. 6). rack1 expression appears in the lateral mesenchyme, a region that gives rise to scleroblasts, where it may be involved in Bmp2-mediated formation of the dermal hemirays. Expression of the transcription factor gene klf 2 is activated in the same region, but a function in dermal bone formation remains uncertain. rack1, together with dusp1, is also expressed in the distal medial mesenchyme. Dusp1 at the tip of the ray and Tms $\beta$-like, which is synthesized by the basal epidermis that envelopes the growing mesenchymal cone, are likely to play roles in the formation of new endothelial cells.

The application of the SSH technique to Xiphophorus fins in early stages of testosterone-induced metamorphosis resulted in the identification of four candidate genes that showed differential expression in induced swords and gonopodia compared to control fins and is the first of this kind to also investigate the expression patterns of these genes at the cellular level in regenerating fins. The subtractive library generated in this study will be important for uncovering additional genes that promote the growth of fin rays or are themselves controlled by testosterone signalling. We further anticipate isolating more candidates that exhibit different temporal profiles or levels of gene ex pression between swords and gonopodia, as exemplified for rack1 and dusp1. In the future, it will be necessary to dissect the molecular functions of these genes, preferably in zebrafish as a genetically accessible model, and to analyse putative interactions between co-expressed genes.

\section{EXPERIMENTAL PROCEDURES}

\section{Fish Stocks and Maintenance}

Juvenile and adult green swordtails $(X$. helleri) were taken from stocks kept at the "Tierforschungsanlage" at the University of Konstanz. Fish were maintained on a 12:12h light:dark cycle at $24^{\circ} \mathrm{C}$ in 110-litre densely planted aquaria and were fed TetraMin flakes and Artemia. 


\section{Testosterone Treatment and Fin Regeneration}

For SSH and $\lambda$-phage cDNA libraries, 120 juvenile individuals of $X$. helleri each, aged between 3 and 6 months, were treated with 17- $x$-methyltestosterone $(1 \mathrm{mg} / \mathrm{ml}$ stock solution in ethanol; Sigma-Aldrich, Munich, Germany) that was added to the water twice a week to a final concentration of $10 \mu \mathrm{g} /$. The 120 individuals were divided into 4 groups of 30 individuals each and were treated in 110-litre tanks. After 1, 2, 4, and 5 days of treatment, $1 / 3$ of the caudal and anal fin was harvested from individuals of one group with a sterile razor blade. For fin amputations, fish were anesthetized by incubation in a solution of $80 \mu \mathrm{g} / \mathrm{ml}$ tricaine (3-aminobenzoicacid-ethylester-methanesulfonate; Sigma-Aldrich, Munich, Germany). For the SSH library, an additional 120 individuals were mocktreated with ethanol and fin tissue was amputated as described above. Testosterone- and ethanol-treated tissue was pooled and used for RNA extraction.

For RT-PCR, 5 to 8 juvenile fish were treated for 2 or 5 days with testosterone, or 5 days with ethanol, followed by the amputation of $1 / 3$ of the distal part of the caudal fin and approximately $2 / 3$ of the anal fin. Caudal and anal fin tissue from the 3 treatment groups was pooled and used for RNA extraction.

For gene expression analysis, up to six juvenile individuals were placed in a 30-litre tank and treated with 17- $\alpha$ methyltestosterone to a final concentration of $10 \mu \mathrm{g} / \mathrm{l}$. After 2 or 5 days of testosterone treatment, fish were anesthetized and approximately $1 / 3$ of the distal part of the caudal fin and approximately $2 / 3$ of the anal fin were amputated.

For regeneration experiments, adult $X$. helleri individuals were anesthetized and $1 / 3$ of the caudal fin was amputated. Subsequently, fins were allowed to regenerate at $24^{\circ} \mathrm{C}$ for 4 days. Fish were anesthetized again and the blastema was removed. Fins and blastemata used for in situ hybridisation were fixed in $4 \%$ paraformaldehyde in PBS (phosphate buffered saline) overnight, transferred to methanol, and stored at $-20^{\circ} \mathrm{C}$ until use.

\section{$\lambda$-Phage cDNA Library Construction}

Total RNA was isolated from caudal and anal fin tissue as described (Zauner et al., 2003). PolyA'-RNA was purified using the Qiagen Oligotex mRNA Mini kit (Qiagen, Hilden, Germany). Five micrograms of PolyA ${ }^{+}$-RNA was used to construct a $\lambda$-phage cDNA library with the ZAP-cDNA Library Construction Kit (Stratagene, Heidelberg, Germany) according to the manufacturer's instructions. The amplified library was stored in SM buffer ( $100 \mathrm{mM} \mathrm{NaCl}, 8$ $\mathrm{mM} \mathrm{MgSO}_{4}, 50 \mathrm{mM}$ Tris- $\mathrm{HCl}, \mathrm{pH} 7.5$ ) with $5 \%$ DMSO at $-80^{\circ} \mathrm{C}$.

\section{Isolation of cDNA From Recombinant $\lambda$-Phages}

Seven hundred and fifty microliters of the amplified cDNA library was treated with $10 \mathrm{U}$ RNAseA and DNAseI (Fermentas, St. Leon-Rot, Germany) prior to phage particle lysis for $10 \mathrm{~min}$ at $37^{\circ} \mathrm{C}$. Phage particles were lysed by adding $150 \mu$ STEP buffer $(0.4 \mathrm{M}$ EDTA, $50 \mathrm{mM}$ Tris-HCl, $\mathrm{pH} 8,1 \%$ SDS) and $100 \mu \mathrm{g}$ Proteinase K (Sigma-Aldrich, Munich, Germany) at $65^{\circ} \mathrm{C}$ for 30 min. DNA was purified by standard methods (Sambrook et al., 1989).

\section{Suppression Subtractive Library Construction}

The SSH library was constructed using the PCR-Select cDNA subtraction kit (Takara Bio/Clontech, Heidelberg, Germany) subtraction, according to the manufacturer's instructions. Two micrograms PolyA ${ }^{+}-$RNA (purified as described above) from testosteronetreated fins were used as tester, and 2 $\mu \mathrm{g}$ PolyA $^{+}$-RNA from ethanol-treated fins were used as driver fractions. The driver pool was subtracted from the tester pool and the subtracted cDNAs were cloned into the pCRII vector using the T/A cloning kit and propagated in $E$.

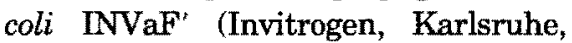
Germany). Subtractive hybridisation efficiency was tested by amplification of a gapdh cDNA fragment from both the subtracted and unsubtracted cDNA pool according to the manufacturer's instructions.

\section{SSH Clone Selection and Sequencing}

DNA was prepared from selected colonies using established procedures (Sambrook et al., 1989). To ensure that as many independent clones as possible were sequenced, inserts were amplified with nested primers supplied with the PCR-Select cDNA subtraction kit (Takara Bio/Clontech, Heidelberg, Germany) and digested with several restriction enzymes with a 4 base-pair recognition site. PCR fragment length and digestion pattern of all clones was compared to each other. If two or more clones showed an identical pattern, only one of these clones was sequenced. Four hundred and six sequences were selected and sequenced using the M13F/ M13R primer set or the supplied nested primer set on an ABI3100 automatic DNA sequencer (Applied Biosystems, Darmstadt, Germany). The sequences were then analysed using "contig express" (Vector NTI 10, Invitrogen). Redundant sequences were eliminated and partly overlapping sequences were grouped into contigs. Independent sequences/contigs, which showed no overlap with other sequences and contig consensus sequences, were identified using BLAST (Altschul et al., 1990) (Supp. Table S1).

\section{RT-PCR}

To detect expression patterns of selected genes, total RNA was isolated from caudal and anal fin tissue as described (Zauner et al., 2003). One microgram of total RNA was transcribed into single-stranded cDNA using the Superscript III reverse transcriptase (Invitrogen, Karlsruhe, Germany). DNA contamination was removed by incubating total RNA with DNAseI (1

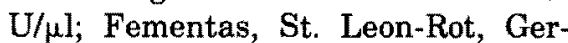
many) for $30 \mathrm{~min}$. cDNA fragments of the selected genes were amplified by PCR using gene-specific primers (Supp. Table S2, which is available online). Primers were designed from SSH clone sequences using "Generunner" (Hastings Software Inc.). $X$. helleri gapdh primers were used for the positive control.

\section{RNA Probe Synthesis}

To obtain fragments of SSH clones with sizes appropriate for generating 
RNA antisense probes, the $3^{\prime}$ ends were amplified from the cDNA library clones using PCR with gene-specific primers (Supp. Table S2). PCR products were gel-purified using the QIAquick Gel Extraction Kit (Qiagen, Hilden, Germany) and cloned into the pCRII-TOPO vector (Invitrogen, Karlsruhe, Germany) for sequencing. Antisense and sense RNA probes were generated using either the digoxigenin or labelling kit (Roche, Mannheim, Germany).

\section{Whole-Mount In Situ Hybridisation}

In situ hybridisation of Xiphophorus fins and blastemata were performed as described (Poss et al., 2000) with several modifications. Pre-hybridisation was done for $4 \mathrm{~h}$ at $68^{\circ} \mathrm{C}$ in formamide solution ( $50 \%$ formamide, $5 \times$ $\mathrm{SSC}, 0,1 \%$ Tween $20, \mathrm{pH}$ to 6 with $1 \mathrm{M}$ citric acid). Post-hybridisation washing steps were initiated at $68^{\circ} \mathrm{C}$ with formamide solution. To block non-specific binding sites, $0.5 \%$ blocking reagent (Roche, Mannheim, Germany) in PBT (PBS + 0.1\% Tween-20, both from Sigma-Aldrich, Munich, Germany) was used. Antibody incubation was done at $4^{\circ} \mathrm{C}$ overnight. After fixation of stained fins/blastemata, the tissue was washed twice for $20 \mathrm{~min}$ in PBT, $20 \mathrm{~min}$ in ethanol/PBT (70:30), and $20 \mathrm{~min}$ in $100 \%$ ethanol and stored at $4^{\circ} \mathrm{C}$.

\section{In Situ Hybridisation on Longitudinal Sections}

In situ hybridisation was performed on longitudinal sections of $16-\mu \mathrm{m}$ thickness from fixed caudal fin blastemata as described (Kuraku et al., 2005) with one exception: For pre-hybridisation and hybridisation, the same solution was used as for whole mount in situ hybridisation. Sections were created with a Reichert-Jung Autocut 2040 Microtome.

\section{Microscopy and Image Editing}

Whole mount fins were analysed using a Zeiss Stemi SV11 Apo. Logitudinal sections were analysed using a Zeiss Axiophot 2. Pictures were taken using the AxioVision software v3.1 (Zeiss) and the digital camera Zeiss AxioCam MRc. Images were processed using Adobe Photoshop 7.0.

\section{ACKNOWLEDGMENTS}

We thank Janine Sieling for animal care, Adina Renz and Amanda Duckworth for help with the expression analysis, Dominique Leo, Elke Hespeler, and Philipp Scholz, who helped to pick and sequence the clones, and members of the Meyer lab for various types of help and discussion. This work was funded by the Landesgraduiertenförderung (LGF) BadenWürttemberg to N.O, and grants from the Deutsche Forschungsgemeinschaft to G.B. and A.M.

\section{REFERENCES}

Altschul SF, Gish W, Miller W, Myers EW, Lipman DJ. 1990. Basic local alignment search tool. J Mol Biol 215:403-410.

Atkins GB, Jain MK. 2007. Role of Kruppel-like transcription factors in endothelial biology. Circ Res 100:1686-1695.

Basolo AL. 1990. Female preference predates the evolution of the sword in swordtail fish. Science 250:808-810.

Basolo AL. 1995. A further examination of a pre-existing bias favouring a sword in the genus Xiphophorus. Anim Behav 50: 365-375.

Basolo AL, Alcaraz G. 2003. The turn of the sword: length increases male swimming costs in swordtails. Proc Biol Sci 270: 1631-1636.

Basolo AL, Trainor BC, 2002. The conformation of a female preference for a composite male trait in green swordtails. Anim Behav 63:469-474.

Bayliss PE, Bellavance KL, Whitehead GG, Abrams JM, Aegerter S, Robbins HS, Cowan DB, Keating MT, O'Reilly T, Wood JM, Roberts TM, Chan J. 2006. Chemical modulation of receptor signaling inhibits regenerative angiogenesis in adult zebrafish. Nat Chem Biol 2:265273.

Bechara IJ, Joazeiro PP, Mari-Beffa M, Becerra J, Montes GS. 2000. Collagenaffecting drugs impair regeneration of teleost tail fins. J Submicrose Cytol Pathol 32:273-280.

Bhattacharya R, Senbanerjee S, Lin Z, Mir S, Hamik A, Wang P, Mukherjee P, Mukhopadhyay D, Jain MK. 2005. Inhibition of vascular permeability factor/vascular endothelial growth factor-mediated angiogenesis by the Kruppel-like factor KLF2.J Biol Chem 280:28848-28851.

Caunt CJ, Rivers CA, Conway-Campbel BL, Norman MR, McArdle CA. 2008. Epidermal growth factor receptor and protein kinase $\mathrm{C}$ signaling to ERK2: spatiotemporal regulation of ERK2 by dual specificity phosphatases. $\mathrm{J}$ Biol Chem 283:6241-6252.
Chakroborty D, Chowdhury UR, Sarkar C, Baral R, Dasgupta PS, Basu S. 2008. Dopamine regulates endothelial progenitor cell mobilization from mouse bone marrow in tumor vascularization. J Clin Invest 118:1380-1389.

Darwin C. 1871. The descent of man, and selection in relation to sex. London: $\mathrm{J}$. Murray.

Diatchenko L, Lau YF, Campbell AP, Chenchik A, Moqadam F, Huang B, Lukyanov S, Lukyanov K, Gurskaya N, Sverdlov ED, Siebert PD. 1996. Suppression subtractive hybridization: a method for generating differentially regulated or tissue-specific $\mathrm{cDNA}$ probes and librar ies. Proc Natl Acad Sci USA 93:60256030.

Dzwillo M. 1962. Einfluss von Methyltestosteron auf die Aktivierung sekundärer Geschlechtsmerkmale über den arttypischen Zustand hinaus (Untersuchungen an xiphophorinen Zahnkarpfen). [Influence of methyltestosterone on the activation of secondary sexual characteristics beyond the species-specific character state (Examination of xiphophorine toothcarps).] Verh Deutsch Zool Gesellsch Wien 151-159.

Dzwillo M. 1964. Sekundäre Geschlechtsmerkmale einiger Xiphophorini unter dem Einfluss von Methyl-testosteron. [Secondary sexual characteristics of some Xiphophorini under the influence of methyltestosterone.] Kosswig-Festschrift15-22.

Eibner C, Pittlik S, Meyer A, Begemann G. 2008. The developmental basis of evolutionary innovation: Inductive signals coordinate the development of a sexually selected trait in swordtail fish. Evol Dev 10:403-412.

Fischer S, Draper BW, Neumann CJ. 2003. The zebrafish fgf 24 mutant identifies an additional level of $\mathrm{Fgf}$ signaling involved in vertebrate forelimb initiation. Development 130:3515-3524.

Gordon M, Cohen H, Nigrelli RF. 1942. A hormone-produced taxonomic character in Platypoecilius maculatus diagnostic of wild $P$. xiphidium. Am Nat 77:569-572.

Grillon C, Rieger K, Bakala J, Schott D, Morgat JL, Hannappel E, Voelter W, Lenfant M. 1990. Involvement of thymosin beta 4 and endoproteinase Asp- $\mathrm{N}$ in the biosynthesis of the tetrapeptide AcSerAspLysPro a regulator of the hematopoietic system. FEBS Lett 274:30-34.

Grobstein C. 1942. Endocrine and developmental studies of gonopod differentiation in certain Poeciliid fishes. II. Effect of testosterone propionate on the normal and regenerating anal fin of adult Platypoecilus maculatus females. $J$ Exp Zool 89:305-328.

Hornshøj H, Bendixen E, Conley LN, Andersen PK, Hedegaard J, Panitz F, Bendixen C. 2009. Transcriptomic and proteomic profiling of two porcine tissues using high-throughput technologies. BMC Genomics 10:30.

Huang WQ, Wang QR. 2001. Bone marrow endothelial cells secrete thymosin beta4 and AcSDKP. Exp Hematol 29:12-18. 
Iovine MK. 2007. Conserved mechanisms regulate outgrowth in zebrafish fins. Nat Chem Biol 3:613-618.

Johnson JB, Basolo AL. 2003. Predator exposure alters female mate choice in the green swordtail. Behav Ecol 14:619-625.

Katogi R, Nakatani Y, Shin-i T, Kohara Y, Inohaya K, Kudo A. 2004. Large-scale analysis of the genes involved in fin regeneration and blastema formation in the medaka, Oryzias latipes. Mech Dev 121:861-872.

Kinney CM, Chandrasekharan UM, Mavrakis L, DiCorleto PE. 2008. VEGF and thrombin induce MKP-1 through distinet signaling pathways: role for MKP-1 in endothelial cell migration. Am J Physio Cell Physiol 294:C241-250.

Kuraku S, Usuda R, Kuratani S. 2005. Comprehensive survey of carapacial ridge-specific genes in turtle implies cooption of some regulatory genes in carapace evolution. Evol Dev 7:3-17.

Laforest L, Brown CW, Poleo G, Geraudie J, Tada M, Ekker M, Akimenko MA 1998. Involvement of the sonic hedgehog, patched 1 and $b m p 2$ genes in patterning of the zebrafish dermal fin rays, Devel opment 125:4175-4184.

Langer WF. 1913. Beiträge zur Morphologie der viviparen Cyprinodontiden. Gegenbauer's Morph Jahrb 47:193-307.

Lee JS, Yu Q, Shin JT, Sebzda E, Bertozzi C, Chen M, Mericko P, Stadtfeld M, Zhou D, Cheng L, Graf T, MacRae CA, Lepore JJ, Lo CW, Kahn ML. 2006. Klf2 is an essential regulator of vascular hemodynamic forces in vivo. Dev Cell 11:845857

Liang P, Averboukh L, Keyomarsi K, Sager R, Pardee AB. 1992. Differential display and cloning of messenger RNAs from human breast cancer versus mammary epithelial cells. Cancer Res 52:6966-6968.

Liu JM, Lawrence F, Kovacevic M, Bignon J, Papadimitriou E, Lallemand JY, Katsoris P, Potier P, Fromes Y, Wdzieczak-Bakala J. 2003. The tetrapeptide AcSDKP, an inhibitor of primitive hematopoietic cell proliferation, induces angiogenesis in vitro and in vivo. Blood 101:3014-3020.

Lu HC, Swindell EC, Sierralta WD, Eichele G, Thaller C. 2001. Evidence for a role of protein kinase $C$ in FGF signal transduction in the developing chick limb bud. Development 128:2451-2460.

Malinda KM, Goldstein AL, Kleinman HK. 1997. Thymosin beta 4 stimulates direc tional migration of human umbilical vein endothelial cells. Faseb J 11:474-481.

Malinda KM, Sidhu GS, Mani H, Banaudha $\mathrm{K}$, Maheshwari RK, Goldstein AL, Kleinman HK. 1999. Thymosin beta4 accelerates wound healing. $J$ Invest Der matol 113:364-368.

McCahill A, Warwicker J, Bolger GB, Houslay MD, Yarwood SJ. 2002. The RACK1 scaffold protein: a dynamic $c o g$ in cell response mechanisms. Mol Pharmacol 62:1261-1273.
Meyer A. 1997. The evolution of sexually selected traits in male swordtail fishes (Xiphophorus: Poeciliidae). Heredity 79: 329-337.

Meyer A, Morrissey JM, Schartl M. 1994. Recurrent origin of a sexually selected trait in Xiphophorus fishes inferred from a molecular phylogeny. Nature 368:539542.

Meyer A, Salzburger W, Schartl M. 2006. Hybrid origin of a swordtail species (Teleostei: Xiphophorus clemenciae) driven by sexual selection. Mol Ecol 15:721-730.

Nechiporuk A, Poss KD, Johnson SL, Keating MT 2003. Positional cloning of a temperature-sensitive mutant emmental reveals a role for sly1 during cell proliferation in zebrafish fin regeneration. Dev Biol 258:291-306.

Nishidate M, Nakatani $Y$, Kudo A, Kawakami A. 2007. Identification of novel markers expressed during fin. regeneration by microarray analysis in medaka fish. Dev Dyn 236:2685 2693.

Oates AC, Pratt SJ, Vail B, Yan Y, Ho RK, Johnson SL, Postlethwait JH, Zon LI. 2001. The zebrafish kIf gene family. Blood 98:1792-1801

Offen N, Blum N, Meyer A, Begemann G. 2008. Fgfr1 signalling in the development of a sexually selected trait in vertebrates, the sword of swordtail fish. BMC Dev Biol 8:98.

Ogino Y, Katoh H, Yamada G. 2004. Androgen dependent development of a modified anal fin, gonopodium, as a model to understand the mechanism of secondary sexual character expression in vertebrates. FEBS Lett 575:119-126.

Padhi BK, Joly L, Tellis P, Smith A, Nanjappa $P$, Chevrette $M$, Ekker M, Akimenko MA. 2004. Screen for genes differentially expressed during regeneration of the zebrafish caudal fin. Dev Dyn 231: 527-541.

Poss KD, Shen J, Nechiporuk A, McMahon G, Thisse B, Thisse C, Keating MT. 2000. Roles for Fof signaling during zebrafish fin regeneration. Dev Biol 222:347-358.

Poss KD, Nechiporuk A, Hillam AM, Johnson SL, Keating MT. 2002. Mps1 defines a proximal blastemal proliferative compartment essential for zebrafish fin regeneration. Development 129, 5141-5149.

Quint E, Smith A, Avaron F, Laforest L, Miles J, Gaffield W, Akimenko MA. 2002. Bone patterning is altered in the regenerating zebrafish caudal fin after ectopic expression of sonic hedgehog and $b m p 2 b$ or exposure to cyclopamine, Proc Natl Acad Sci USA 99:8713-8718.

Rosenthal GG, Evans CS. 1998. Female preference for swords in Xiphophorus helleri reflects a bias for large apparent size. Proc Natl Acad Sci USA 95:44314436.

Rosenthal GG, Garcià de Leon FJ. 2006. Sexual behavior, genes, and evolution in Xiphophorus. Zebrafish 3:85-90.
Rosenthal GG, Martinez TYF, Garcià de Leon FJ, Ryan MJ. 2001. Shared preferences by predators and females for male ornaments in swordtails. Am Nat 158: 146-154.

Roth LW, Bormann P, Bonnet A, Reinhard E. 1999. beta-thymosin is required for axonal tract formation in developing zebrafish brain. Development 126:13651374

Sambrook J, Fritsch EF, Maniatis T. 1989. Molecular cloning: a laboratory manual. Cold Spring Harbor, NY: Cold Spring Harbor Laboratory Press.

Schebesta M, Lien CL, Engel FB, Keating MT. 2006. Transcriptional profiling of caudal fin regeneration in zebrafish. Sci World J 6:38-54.

Smith A, Avaron F, Guay D, Padhi BK, Akimenko MA. 2006. Inhibition of BMP signaling during zebrafish fin regeneration disrupts fin growth and scleroblast differentiation and function. Dev Biol 299:438-454.

Smith A, Zhang J, Guay D, Quint E, Johnson A, Akimenko MA. 2008. Gene expression analysis on sections of zebrafish regenerating fins reveals limitations in the whole-mount in situ hybridization method. Dev Dyn 237:417-425.

Teng CH, Huang WN, Meng TC. 2007. Several dual specificity phosphatases coordinate to control the magnitude and dura tion of JNK activation in signaling response to oxidative stress. J Biol Chem 282:28395-28407.

Whitehead GG, Makino S, Lien CL, Keating MT. 2005. fgf 20 is essential for initiating zebrafish fin regeneration. Science 310:1957-1960.

Yamada S, Wirtz D, Coulombe PA. 2002 Pairwise assembly determines the in trinsic potential for self-organization and mechanical properties of keratin filaments. Mol Biol Cell 13:382-391.

Zakrzewicz A, Hecker M, Marsh LM Kwapiszewska G, Nejman B, Long L, Seeger W, Schermuly RT, Morrell NW, Morty RE, Eickelberg O. 2007. Receptor for activated $\mathrm{C}$-kinase 1, a novel interaction partner of type II bone morphogenetic protein receptor, regulates smooth muscle cell proliferation in pulmonary arterial hypertension. Circulation 115:2957-2968.

Zander CD, Dzwillo M. 1969. Untersuchungen zur Entwicklung und Vererbung des Caudalfortsatzes der Xiphophorus-Arten (Pices). IInvestigations regarding development and inheritance of the caudal process of Xiphophorus species (Pisces).] Z Wissenschaftliche Zool 178:276-315.

Zauner H, Begemann G, Mari-Beffa M Meyer A. 2003. Differential regulation of $m s x$ genes in the development of the gonopodium, an intromittent organ, and of the "sword," a sexually selected trait of swordtail fishes (Xiphophorus). Evol Dev $5: 466-477$ 